\title{
Retrospective clinicopathological analysis of scar endometriosis and its surgical management
}

\author{
Kavitha Yogini Duraisamy ${ }^{1}$, Devi Balasubramaniam¹, \\ Karthikha Ravi ${ }^{1 *}$, Aravinth Subramaniam²
}

\begin{abstract}
${ }^{1}$ Department of Endogynaecology, ${ }^{2}$ Department of Pathology, Gem Hospital and Research Centre, Coimbatore, Tamil Nadu, India
\end{abstract}

Received: 12 December 2020

Accepted: 13 January 2021

\author{
*Correspondence: \\ Dr. Karthikha Ravi, \\ E-mail: karkate29@gmail.com
}

Copyright: ( $\odot$ the author(s), publisher and licensee Medip Academy. This is an open-access article distributed under the terms of the Creative Commons Attribution Non-Commercial License, which permits unrestricted non-commercial use, distribution, and reproduction in any medium, provided the original work is properly cited.

\begin{abstract}
Background: Scar endometriosis is a rare form of extrapelvic endometriosis. It is defined as presence of endometrial glands and stroma in the abdominal wall. They have a variable clinical presentation and present to various doctors. Abdominal mass along with cyclical pain is pathognomic of scar endometriosis. Objective was to analyse the clinical presentation and surgical outcomes of scar endometriosis.

Methods: It was a retrospective observational study. We have collected records of 28 patients of scar endometriosis managed at GEM Hospital over a period of 3 years. Patients demographic features, previous surgery, clinical findings, surgical findings, association with pelvic endometriosis as noted on diagnostic laparoscopy, need for mesh, recurrence rate on follow up were noted.

Results: Mean age of patients was 32.1 years. History of previous caesarean surgery/hysterotomy was present in all patients. Major clinical presentation was cyclical pain. MRI or USG was done and abdominal wall lesions were demonstrated in all cases. Diagnostic laparoscopy was done in 26 of these patients and showed associated endometriosis in 9 patients. Plane of endometriosis was found to be subcutaneous for 9 cases, sheath in 7 and muscular in 12 cases. HPE was proven in all cases.

Conclusions: Scar endometriosis is rare. High index of suspicion is needed for diagnosis, especially in cases of previous caesarean sections. MRI and USG are useful tools for diagnosis. Complete wide local excision of scar endometriosis is the primary modality of treatment. Diagnostic laparoscopy along with the procedure is helpful in diagnosing associated pelvic endometriosis.
\end{abstract}

Keywords: Extrapelvic endometriosis, Scar endometriosis

\section{INTRODUCTION}

Endometriosis is the presence of endometrial glands and stroma outside the endometrial cavity. Scar endometriosis is a rare entity reported in the gynecological literature with an estimated incidence of $0.03-0.15 \%$, of all cases of endometriosis. The most accepted theory is the iatrogenic transplantation of endometriotic implants to the wound edge during abdominal or pelvic surgeries. It may be confined to the superficial layers of the abdominal or pelvic wall (skin, subcutaneous tissues) and often infiltrates the deep layers, commonly the rectus muscle. The preferred treatment is wide surgical excision with clear margins to prevent local recurrence. Among women with scar endometriosis, $14.3-26 \%$ have concomitant pelvic endometriosis. ${ }^{1}$ In our centre we do diagnostic laparoscopy to rule out pelvic endometriosis and to look for peritoneal involvement in patients with scar endometriosis. $^{2}$

The objective of our study was to analyse the clinical presentation and surgical outcomes of scar endometriosis. 


\section{METHODS}

This was a retrospective observational study. All patients operated in our centre for scar endometriosis in the previous 3 years (January 2017-December 2019) were included in the study. Patients age, history of previous surgery, duration between previous surgery and presentation of symptoms, duration between onset of symptoms and intervention, clinical findings, imaging findings, intra operative findings, association with pelvic endometriosis as noted on diagnostic laparoscopy, histopathology, recurrence on follow up were noted. Consent was obtained from all patients.

\section{RESULTS}

Of the total 28 patients, 13 presented to us, while 15 patients presented to the general surgery department and referred to us. Except one patient with recurrent scar endometriosis, all others patients were diagnosed as scar endometriosis first at our centre. Mean age of patients was 32.1 years. History of previous caesarean surgery/hysterotomy was present in all patients (Table 1).

Table 1: Patient demography.

\begin{tabular}{|ll|}
\hline Parameters & $\mathbf{N}(\%)$ \\
\hline Mean age & 32.1 years \\
\hline Previous surgery & \\
\hline 1 LSCS & $8(28.5)$ \\
\hline 2 LSCS & $18(64.3)$ \\
\hline Hysterotomy & $2(7.2)$ \\
\hline Symptoms & \\
\hline Swelling with cyclical pain & $15(53.5)$ \\
\hline Cyclical pain only & $10(35.7)$ \\
\hline Non-cyclical pain (1 acute pain) & $3(10.8)$ \\
\hline Examination & \\
\hline Nodularity with tenderness & $16(64.2)$ \\
\hline Only nodularity & $3(10.8)$ \\
\hline Negative & $7(25)$ \\
\hline Mean asymptomatic period & 34.6 months (range \\
\hline Mean duration of symptoms & $3-90$ months) \\
\hline
\end{tabular}

History of caesarean was present in 26 patients, while hysterotomy was present in 2. Pfannensteil incision was noted in 25 patients and midline vertical scar noted in 3 patients. $15(53.5 \%)$ patients presented with only cyclical pain over the scar, $10(35.7 \%)$ patients had swelling with cyclical pain while non-cyclical pain was noted in 3 $(10.8 \%)$ patients. On examination nodularity and tenderness was noted 18 patients (64.2\%), only nodularity was noted in $3(10.8 \%)$ patients and no clinical lesions were noted in 7 (25\%) patients.

Mean duration of symptoms was 28.1 months (range 1141). Mean asymptomatic period was 34.6 months (range 3-90 months). USG picked up lesion in all patients. MRI was done 11 patients, for those with suspicion of deeper involvement (Table 2).

Table 2: Investigations.

\begin{tabular}{|ll|}
\hline $\begin{array}{l}\text { USG: Mean of maximum } \\
\text { diameter of the lesion }\end{array}$ & $4.3 \mathrm{~cm}(\mathbf{1 . 5}-7.5 \mathrm{~cm})$ \\
\hline MRI & 11 \\
\hline FNAC/others & Nil \\
\hline
\end{tabular}

Laparoscopy was done in 26 patients (Figure 1).

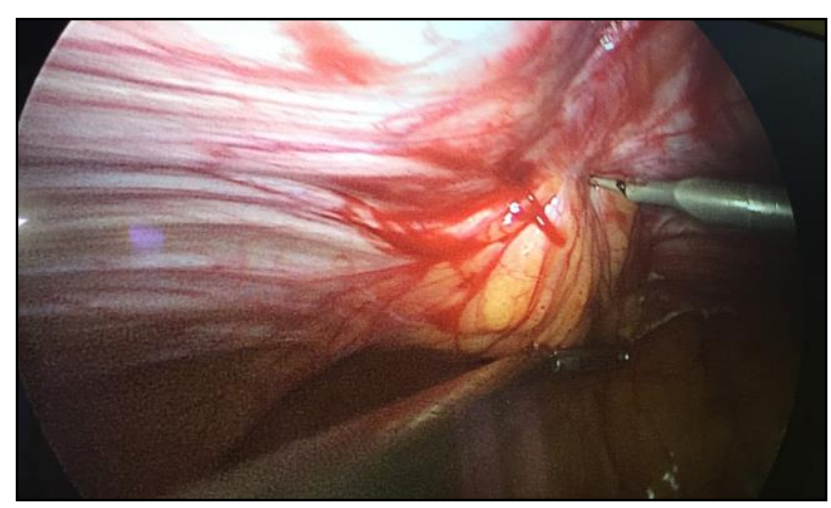

Figure 1: Laparoscopic picture of peritoneal puckering.

Associated pelvic endometriosis was noted in 9 patients $(34.6 \%)$ (Table 3). No evidence of endometriosis was noted in rest of the 17 patients $(65.4 \%)$.

Table 3: Intraoperative findings and follow up.

\begin{tabular}{|ll|}
\hline Parameters & N $(\%)$ \\
\hline Diagnostic laparoscopy done & $26 / 28$ \\
\hline Pelvic endometriosis & $9(34.6)$ \\
\hline No evidence of pelvic endometriosis & $17(65.4)$ \\
\hline Plane of involvement & \\
\hline Subcutaneous & $9(32.2)$ \\
\hline Subcut+ rectus sheath & $7(25)$ \\
\hline Subcut + sheath + muscular & $12(42.8)$ \\
\hline Fascial defect closure & \\
\hline Mesh & 1 \\
\hline Suture & 18 \\
\hline On follow up- nil recurrence & 24 \\
\hline Lost to follow up & 4 \\
\hline
\end{tabular}

In wide local excision, $1 \mathrm{~cm}$ margin clearance was obtained in 26 patients while in 2 patients $0.5 \mathrm{~cm}$ margin was obtained (Figure 2 and 3 ).

Rectus sheath closure was needed in 19 patients. All patients had subcutaneous involvement while rectus sheath was involved in 7 and (25\%) intra muscular involvement was noted in 12 patients $(42.8 \%)$. 1 patient required mesh closure while in 10 patients suturing with noabsorbable suture material (number 1 loop ethilon/ 
number 1 prolene) was done. Size of endometriotic lesions varied from 1.5-7.5 cm. Histopathology was proven for all cases (Figure 4). On follow up, no recurrences were noted in 25 patients, 3 were lost to follow up.

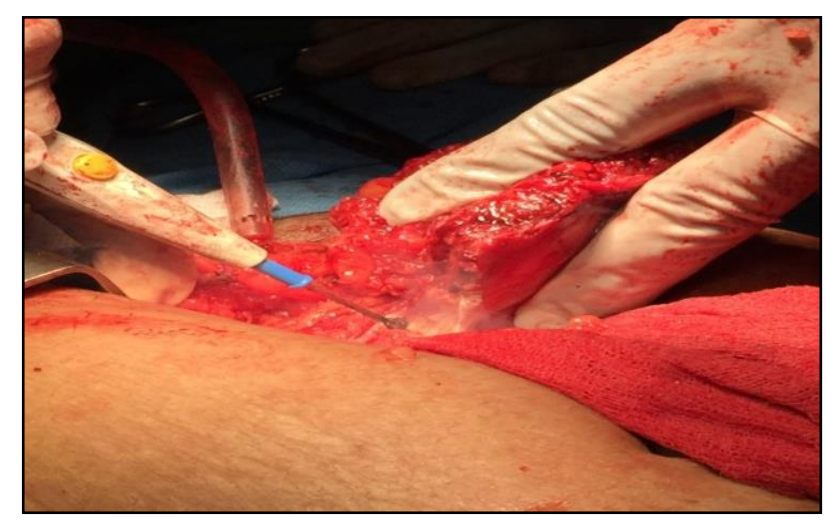

Figure 2: Wide local excision of scar endometriosis.

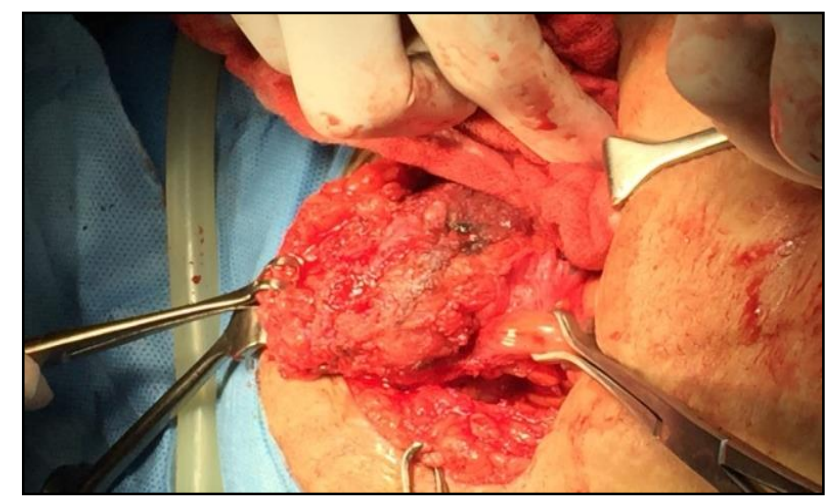

Figure 3: excision of scar endometriosis.

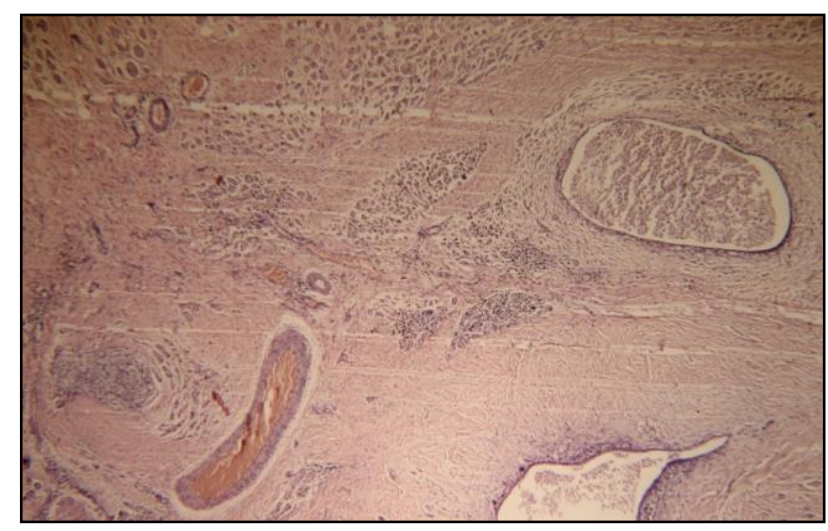

Figure 4: Histopathology.

\section{DISCUSSION}

Scar endometriosis is a rare and often misdiagnosed entity. It usually follows uterine surgery though it may occur spontaneously occasionally. Incidence is estimated around $0.03 \%-0.1 \% .^{3}$ Most commonly accepted theory is the direct implantation theory. Some studies suggest hysterotomy has a higher incidence for scar endometriosis than caesarean section. It is likely that during hysterotomy particularly with a classical incision, the decidua of early pregnancy spills readily and implants itself directly into the abdominal wound. After being transported to a susceptible wound, the inoculum may proliferate. Steck et al suggest that the decidual cells do not themselves proliferate. ${ }^{4}$ It is more likely that they stimulate imitative metaplasia (cellular replication) in the lodging tissue that forms the endometriosis.

The average age of women with scar endometriosis was 32.1 years and is similar to those of other studies where mean age was 31 years. ${ }^{5}$ Scar endometriosis is hence said to be predominant in the reproductive age group. History of previous uterine surgery was present in all our cases

The most common symptom that patients present with is cyclical pain near scar site. Associated swelling may also be felt by the patient. Nodularity was felt on clinical examination in 21 patients, 18 of which were also tender. This is the reason that they present to general surgeons. Association with cyclical pain is a characteristic symptom. But in other patients it is important to differentiate them between other swellings like subcutaneous cyst, hematoma, lymphoma, soft tissue sarcoma or desmoid tumor by further investigations.

The asymptomatic period between previous surgery was 34.6 months, 2.8 years (range 3-90 months), signifies that there is always a time interval after which symptoms start in scar endometriosis. This finding is similar to review by Horton where the average is 3.6 years. ${ }^{5}$ Mean duration between onset of symptoms till diagnosis was 8.1 months (1-141 months). This could be because of the nonspecific nature of symptoms or could be because of delay in diagnosis by the doctor.

High index of suspicion will help in further evaluation. USG is highly reliable and also helps in mapping of the lesion before surgery. In all our cases USG was helpful in measuring the masses which ranged between $1.5 \mathrm{~cm}$ and $7.5 \mathrm{~cm}$, mean size diameter being $4.3 \mathrm{~cm}$. In 11 patients where there was suspicion of deep involvement and MRI was done to look for extent. Muscular involvement was noted in MRI for all the patients. FNAC may help if we have doubt in the diagnosis. Since clinical diagnosis, USG and MRI was used to differentiate between other swellings, we had not used FNAC. The reason for USG picking up all the lesions could be because specific abdominal wall USG was requested due to clinical suspicion.

Diagnostic laparoscopy (Figure 1) followed by wide local excision of mass (Figure 2 and 3) was done in 26 patients out of 28 , while the other 2 only wide local excision was done. On laparoscopy associated pelvic endometriosis was noted in 9 patient (34.6\%). This is higher than $25.9 \%$ as reported by other studies. ${ }^{1}$ The overall incidence of pelvic endometriosis is $8-15 \%$ in the reproductive age 
group. $^{6}$ This means that the incidence of pelvic endometriosis could be higher in women with scar endometriosis. Wide local excision with a margin of $1 \mathrm{~cm}$ was given in 27 of the patients and for 1 patient $0.5 \mathrm{~cm}$ margin was given. Rectus sheath involvement was present in $25 \%$ and muscular involvement was noted in $42.8 \%$. This will help us to anticipate general surgeons help in fascial defect closure with mesh or direct closure. Mesh closure was done in one patient. Medical management was not given in any patients preoperatively. Postoperative hormones were given in cases with associated symptomatic pelvic endometriosis.

Recurrence was not noted in 25 of the patients followed up till date. 3 patients were lost to follow up.

\section{CONCLUSION}

Scar endometriosis is a rare condition with varied presentation and presents as a diagnostic dilemma. High index of suspicion is needed for the diagnosis. Reproductive age, previous uterine surgery, cyclical symptoms in a scar are the characteristic findings. USG is a good modality for diagnosis, while MRI augments further details. Wide local excision with good margin is definitive and decreases recurrence. Association of pelvic endometriosis should always be kept in mind.

\section{ACKNOWLEDGMENTS}

We would like to thank our Chairman Dr. C. Palanivelu, Chairman, Gem Hospital and Research Centre for supporting us in this study.
Funding: No funding sources Conflict of interest: None declared

Ethical approval: The study was approved by the Institutional Ethics Committee

\section{REFERENCES}

1. Rani PR, Soundararaghavan S, Rajaram P. Endometriosis in abdominal scars- review of 27 cases. Int J Gynaecol Obstet. 1991;36(3):215-8.

2. Fazari A, Paulose L, Maqbool S, Malik Z, Raman L. Scar endometriosis- case report. Open J Obstet Gynecol. 2018;08(12):1205-9.

3. Wolf G, Singh K. Cesarean scar endometriosis. Obstet Gynecol Survey. 1989;44(2):89-95.

4. Steck W. Cutaneous endometriosis. JAMA. 1965;191(3): 167 .

5. Horton JD, Dezee KJ, Ahnfeldt EP, Wagner M. Abdominal wall endometriosis: a surgeon's perspective and review of 445 cases. Am J Surg. 2008;196(2):207-12.

6. Scholefield HJ, Sajjad Y, Morgan PR. Cutaneous endometriosis and its association with caesarean section and gynaecological procedures. J Obstet Gynaecol. 2002;22(5):553-4.

Cite this article as: Duraisamy KY,

Balasubramaniam D, Ravi K, Subramaniam A.

Retrospective clinicopathological analysis of scar endometriosis and its surgical management. Int J Reprod Contracept Obstet Gynecol 2021;10:658-61. 